\title{
AHP METHOD OF DETERMINATION OF RELATIVE WEIGHTS FOR JUDGED ITEMS AND JUDGES IN A JUDGEMENT PROCESS
}

\begin{abstract}
The aim of this paper is to propose an alternative method to assist judgement processes. This method is based on the creation and conjugated usage of relative degrees of importance (weight) of the judged items and the relative degree of importance (weight) of the judges. The score given by the judge to the item will be influenced by these two weights. The relative weights of the judged items are defined by experts. The relative weights of the judges are defined by specific qualification criteria. It is paramount to consider these two factors in a judgement process using reliable metrics and parameters. The intention is to make the final result of a judgement, with respect to the judged items, have a greater representation in reality. This methodology can, at first, be used in any judgement process. The methodology uses descriptive and exploratory researches.
\end{abstract}

Keywords: AHP, judgement method, relative weights.

\section{Introduction}

The results of a judgement can have critical consequences for people and enterprises. The possibility of having high subjectivity in judgement processes influencing the results has motivated me to do this work. How can this subjectivity be decreased? The aim of this paper is to propose an alternative method to assist judgement processes, considering the relative degrees of importance (weight) of the judged items and the relative degree of importance (weight) of the judges. This study is important because the results of the judged items can give a better representation of reality.

\section{Literature Review}

Four multicriteria decision-making methods were researched: Aggregated Indices Randomization Method (AIRM) by the paper "Multicriteria estimation of probabilities on basis of expert non-numeric, non-exact and non-complete knowledge". Hovanov N.(2007), European Journal of Operational Research; Analytic Network Process (ANP); Analytic Hierarchy Process (AHP) of Thomas L. Saaty; and Best Worst Method (BWM) by the paper "Best-Worst Multi-Criteria Decision-Making Method", Rezaei, J. (2015), Omega, 53, 49-57. The AHP method has a structure which determines the criteria and their weights based on the preferences of the decision-makers, converting human judgements into numeric values to build a decision-making model allowing a pairwise comparison of the alternatives.

\section{Objectives}

The aim of this paper is to propose an alternative method to assist judgement processes, considering the relative degrees of importance (weight) of the judged items and the relative degree of importance (weight) of the judges. 


\section{Research Design/Methodology}

Based on the literature of Thomas L. Saaty, Triantaphyllou, Liebscher and Calder, among others, and comparing different multicriteria decision-making models, it has been concluded that in a judgement process both the items judged and the judges can have different degrees of importance. These two attributes are important and must be considered according to the purpose and criticality of the judgement. To illustrate the model, three supposed items to be judged, two supposed experts to define weights to the items and two supposed judges to judge the items were used. Initially, the weights of the items were defined, then the weights of the judges were defined based on three qualification criteria. Finally, the model was tested using the supposed scores given to the items by the judges being influenced by the weights of the items and judges.

\section{Data/Model Analysis}

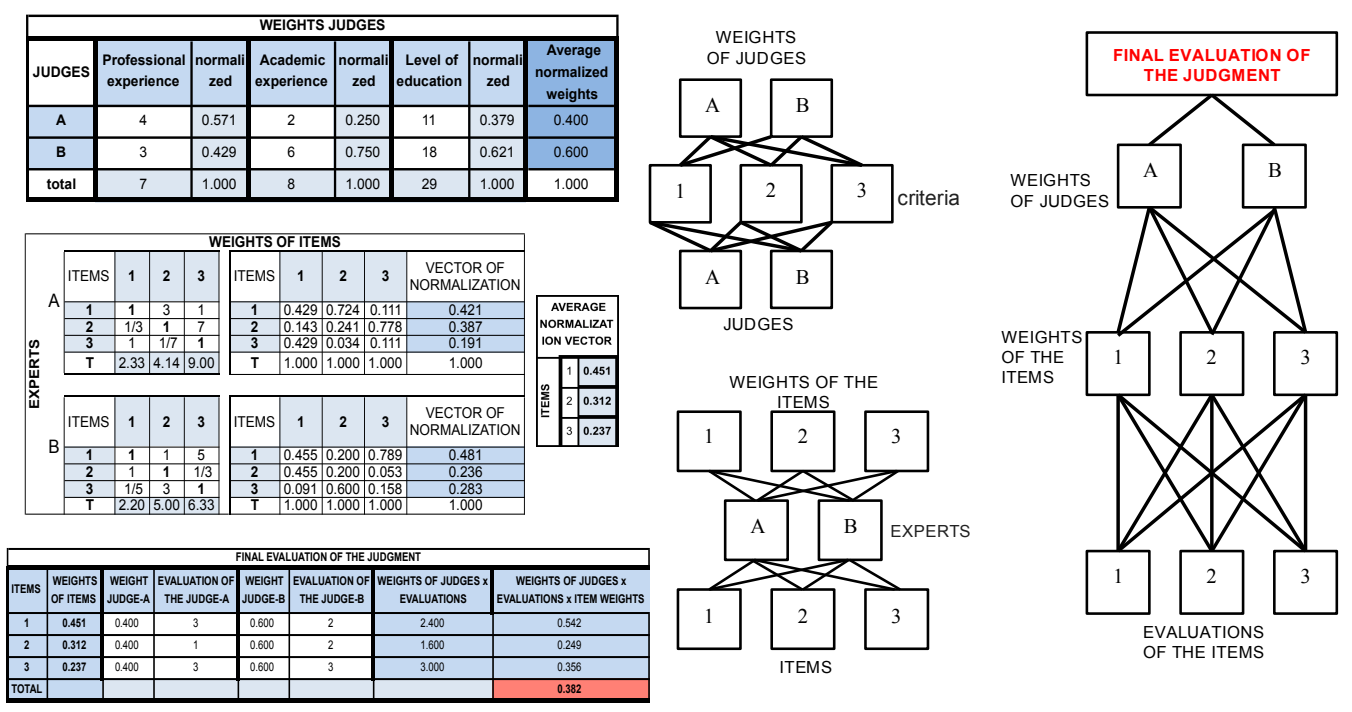

\section{Conclusions}

The method proposed, which suggests two main changes, enables a decrease in the subjectivity in a judgement process which can significantly influence the results in relation to the representativity of the perceptions of judges and importance of the judged items. Moreover, this paper concludes that it is possible to enhance processes or methods of assessment of people, enterprises, objects, etc., considering the relative degrees of importance of significant factors that influence a specific context or situation.

\section{Key References}

Triantaphyllou, E. (2000). Multi-Criteria Decision Making: A Comparative Study. Dordrecht, The Netherlands: Kluwer Academic Publishers (now Springer). p. 320.

Saaty, Thomas L. (2009). An Essay on How Judgment and Measurement are Different in Science and in Decision Making, IJAHP ESSAY, Vol 1, Issue 1

Liebscher,P. Quantity with quality? Teaching quantitative and qualitative methods in a LIS Master's program. Library Trends, v. 46, n. 4, p. 668-680, Spring 1998.

Calder, B. Focus group and the nature of qualitative marketing research. Journal of Marketing Research, n. 14, p. 353-64, Aug. 1977. 